\title{
Moving towards a university wide implementation of an ePortfolio tool
}

\author{
Sarah Lambert and Linda Corrin \\ University of Wollongong
}

\begin{abstract}
The University of Wollongong has been strategically exploring ePortfolios since 2002. Building on lessons learnt from student trials across two different disciplines in 2002/3 and 2006, the project team is on the verge of implementing a university wide ePortfolio tool customisable for all students across all faculties. This paper describes the steps taken on the road thus far, including a description and justification of a new project structure and consultative framework developed to guide the implementation.
\end{abstract}

\section{Introduction}

In recent years electronic portfolios (also known as ePortfolios) of student work have become more popular, taking over from paper based versions (Avraamidou \& Zembal-Saul, 2006). Benefits include better educational outcomes afforded by the ability to annotate and contextualise items in the portfolio, as well as the ability to cut and paste text into other applications for a multitude of purposes.

The University of Wollongong (UoW) has been strategically exploring ePortfolios since 2002 with student trials in 2002/3 and 2006. ePortfolios facilitate reflection, recording and articulation of the university experience and hence have connections to our capacity (as the Australian University Quality Audit recommends) to "embed the Graduate Attributes into the curriculum and into teaching and assessment practices" as well as draw on the individual's whole of life experiences outside the curriculum. In addition, some accrediting bodies, such as the NSW Institute of Teachers and the Australian Medical Association, have made it compulsory for graduating students to show evidence of learning outcomes against complex sets of over 40 Professional Skills criteria.

In December 2005 it was proposed to make available a university wide ePortfolio system, based on ePortfolio trials conducted in 2002/03 and 2006. While a generic ePortfolio may be made available to all students in 
the future, the first priority will be to integrate the UoW ePortfolio into academic programs of study, with cohorts of students having a discipline specific and customised ePortfolio made available to them after negotiation with Faculties.

\section{Portfolios and ePortfolios: A literature review}

Research into portfolios for student learning and assessment has been going on for over 25 years (Barrett, 2003). From an educational perspective, portfolios provide a mechanism to encourage student reflection which has the potential to assist with students' understanding of their own learning.

Unlike a static, paper based portfolio, ePortfolios allow information to be stored, accessed, updated and presented in various electronic and paper based formats (Song et al, 2004). ePortfolios can take a number of forms, but at their core is the facility to enable students to store and update records of their achievements both in terms of the development of discipline specific skills and the acquisition of broader Graduate Attributes (Luca et al, 2003). Reflections, self evaluation and personal development are central themes to ePortfolio development with the emphasis of most ePortfolio implementations being on helping students to understand their own personal development and identify areas where improvement is needed (DiBiase, 2002). The features of the UoW ePortfolio are in line with these trends, focussing on:

1. Skills development including Graduate Attributes,

2. Recording achievements, and

3. Personal development.

Barrett (2001) identifies three general purposes of ePortfolios in educational settings. Learning ePortfolios are formative in nature and focus on personal development through the use of self evaluation and reflection. ePortfolios can also be used as a tool of assessment where students are required to show through selection and reflection on their learning activities how skills and knowledge development have been demonstrated. The third general purpose of ePortfolios is focused on the presentation of skills and attributes for employment contexts.

The push for the implementation of ePortfolios can often come from multiple arenas within an institution (Reardon et al, 2005) and can also come from national or governmental organisations (Ravet, 2005). At the University of Wollongong two main driving forces are present. The first is the University's commitment to the attributes of a University of Wollongong graduate expressed in a policy that filters down to all levels of the teaching and learning environment. The importance of this policy was 
made very clear in the University's audit by AUQA in 2005. The Careers Service is one of the primary units responsible for implementing such policies and their programs make the Graduate Attributes explicit for students. The Careers Service also recognise the potential that ePortfolios have in helping students prepare for the process of job seeking.

Another driving force comes from those disciplines such as Design and Engineering whose extensive use of paper based design logs creates an existing "portfolio culture" as well as those such as Education and Medicine who are guided by requirements set by professional bodies for the collection of materials to evidence discipline specific skills development. The combination of these influences has resulted in the decision to adopt a system which can be implemented across the whole institution but is flexible enough to meet the diverse needs of the different stakeholders.

Whilst the trend for ePortfolio adoption is on the increase, the methods for implementing such tools across entire institutions are many and varied. Central to successful implementation of ePortfolios, according to Roberts et al (2005), is the consideration of the perspectives of the multiple stakeholders involved in the process, the collaboration of pedagogical, administrative and technical processes and integration of technologies into effective frameworks. Gathercoal et al (2002) identified twelve critical factors for successful implementations of ePortfolios, and this list - which is discussed and reconfigured later in the paper - fits tightly with the trial outcomes and concerns of faculty and management at the University of Wollongong, and therefore with our research efforts.

Our research extends these themes and provides new information of the management of institution-wide educational technology implementations for teaching and learning.

\section{Background to the project}

\section{Attributes and Opportunities Portfolio}

In 2002 Martin Smith from the UoW Careers Service and Kate Bowles from the Faculty of Arts successfully applied for internal project funds to develop and trial an online ePortfolio, after early experiments with reflective stimulus questions delivered via the Online Learning Management System, WebCT. The primary author joined the team at this point and designed the first trial ePortfolio using a Filemaker Pro database with data entered via standard webpage forms. 
The 2002/03 trial ePortfolio gave students the ability to reflect on their learning experiences across three domains (Work, University, and Community) and against eight common graduate employment criteria which mapped against the UoW Graduate Attributes (see Figure 1).

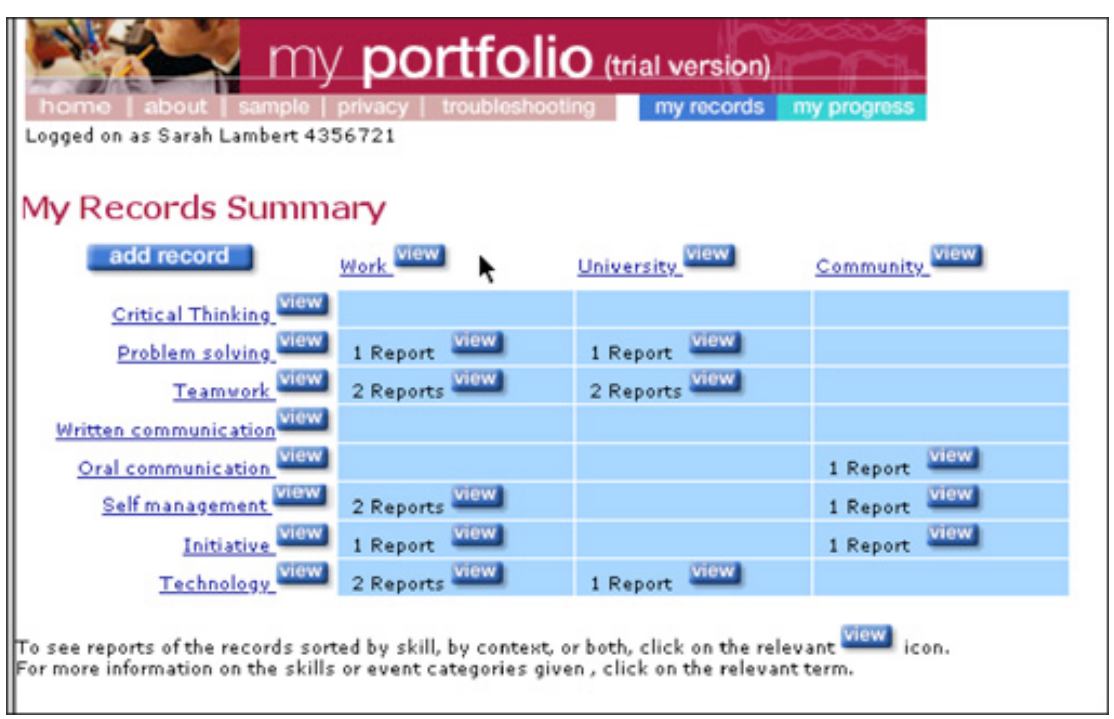

Figure 1: The Attributes and Outcomes Portfolio (2003)

The CARL framework (Context, Action, Response, Learning) structured the major text entry fields for the student to describe their learning experience, with an additional 'summary' field provided to allow a quick overview of the record, essential for making sense of multiple records later. The CARL framework is an important scaffold for learning (Wood et al, 1976) and has been maintained in later trials as it has been shown in both trials to be effective in supporting the students in writing an effective and wellstructured reflection of the learning event (see Figure 2).

The trial over two different student cohorts in the Faculty of Arts was a success and identified many benefits to students, academics and the University. The trial also identified three pathways or take up models for future institution-wide implementation:

1. Academic integration via the curriculum (where subject coordinators choose to use the Portfolio tool either in assessment tasks, or to recommend the use of the tool in order to make visible the graduate attribute acquisition occurring in the curriculum).

2. Prompted (e.g., by the Careers Service or Learning Development, or by academic advisors outside the context of specific subjects). 
3. Self managed (optional and available to all students, and embedding sufficient instruction and help files in the tool itself to enable interested students to use the portfolio without specific support or training).

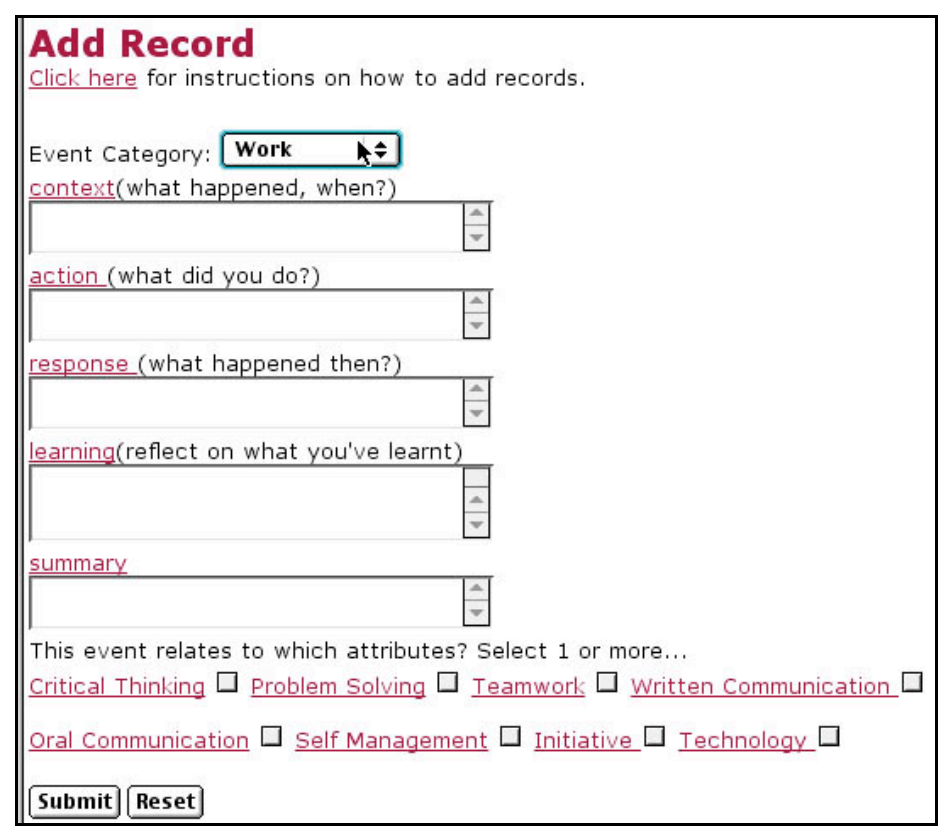

Figure 2: Input screen to the 2003 trial ePortfolio showing the CARL framework and use of pulldown menu and checkboxes to 'tag' each record

Of these take up models, the first two were favoured as the most transformative in terms of impacting students' engagement, but also requiring the largest ongoing effort to realise the potential that ePortfolios have to positively impact teaching and learning on campus. This first trial also identified gaps in many students' skills that would need to be addressed. More explicit teaching of both reflective practice (writing reflectively about learning) alongside training in the technical aspects of ePortfolios was required.

\section{6 wiki trial}

In the autumn semester of 2006, approximately 300 students from Performance and Journalism disciplines trialled an ePortfolio using "wikion-a-stick" (memory stick) technology. The wiki allowed students to edit a webpage and the memory stick allowed them to store and transport their work to numerous locations. 
As Augar et al have noted, "Ward Cunningham used the word wiki (the Hawaiian word meaning quick) to name the collaborative tool he developed for use on the Internet in 1994. Wikis are fully editable websites. Users can visit, read, re-organise and update the structure and content (text and pictures) of a wiki as they see fit." (Augar et al, 2004, 95).

There are over 100 wikis currently available on the Internet. The particular wiki chosen for the 2006 trial was based on the Tiddlywiki open source product which is designed for individuals to maintain their own webpage. This version does not feature collaborative functionality. The Tiddlywiki was chosen for its ease of customisation and low cost. The product was free and thus the only 'cost' in the 2006 trial was the primary author's time to customise for each trial student cohort - half a day to a day's work for each customisation. The wikis provided to students as the trial ePortfolio tool were highly customised to allow students to document and reflect on their progress towards achieving the University's Graduate Attributes as well as a handful of discipline specific skills. The wiki could also provide active URLs and links to samples of students' work.

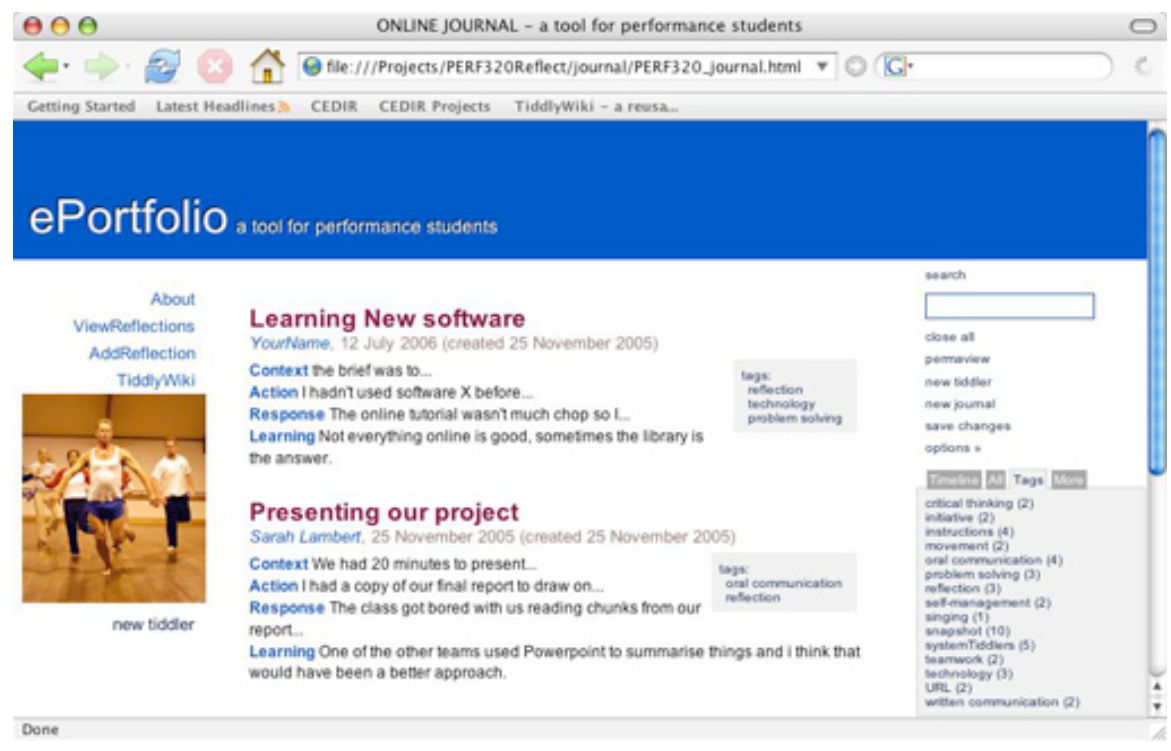

Figure 3: A screen shot of the ePortfolio for Performance students

The aims of the 2006 trial which were successfully met were three-fold:

1. To keep dialogue and momentum going on campus about Graduate Attributes and ePortfolios; 
2. To provide students with an electronic resource for their journal assignments, responding to academic requests; and

3. To investigate the latest wiki and blog (web log or journal) tools with potential for use as an ePortfolio.

Based on the results of the 2002/3 trial we were aware that staff and students have a range of computer skills and confidences, and so adequate time must be set aside for explicit teaching of not only the tool but also the reasons for using it. As McKinnon has noted, "students continue to require significant introduction to the technology in order to overcome the associated anxiety" (MacKinnon, 1999, p.3).

Therefore, substantial orientation and 'getting started' sessions were provided, and the support package provided for students of the trial cohorts typically consisted of:

1. A one hour orientation session in a computer lab in the class time, including a discussion regarding the requirements of potential employers for evidence against job selection criteria such as the Graduate Attributes.

2. A one page step by step handout identifying basic 'getting started' activities such as adding name and details, rating current Graduate Attribute skills level, and practicing one or two learning reflections using the CARL framework.

3. A one page overview of the navigation mechanisms and browser specifications of the wiki including screen shots.

4. In some cases a follow up session was booked in the computer labs in tutorial time in week six to provide support for those who were still unsure on how to use the tool.

5. In addition, the computer lab staff and management were briefed on the browser requirements and provided with the help and support documentation to allow them to help students who may present with problems in the labs out of class time.

As per the 2002/3 trial, substantial time was also spent with the academics involved. The author met regularly with subject coordinators to design the assessment task for their students, and to customise the tool appropriately.

Survey evaluations (sample size $\mathrm{N}=68$ ) identified that the ability to reflect on Graduate Attributes and Professional Skills and the opportunity to learn new technology skills were worthwhile student outcomes of using the ePortfolio. The orientation sessions provided were also rated highly by the students. As for the 2002/3 trial, reflective writing practice did not come naturally to most students and they required quite a bit of explicit teaching as well as practice at it before becoming comfortable. A small number of 
students steadfastly failed to see the point in spending the time reflecting on their learning, an attitude also present to a small degree in the earlier trial.

The wiki technology chosen was not popular with students due to their desire to work on the ePortfolio at home and work, while their computers at these non-university locations were not configured adequately. As Lamb $(2004,48)$ observed "there are no unified set of software characteristics that are shared by all wikis" and, as in the case of the trial wiki, many require very specific computer configurations. One key recommendation regarding the technology behind an ePortfolio tool was to move to a server solution, meaning that the scripting complexity that provides functionality should be handled on university computer servers and not handled at the users' desktop.

A smaller trial was also conducted as part of a Careers Service Program, where the ePortfolio provided was a structured Word document. The CARL framework was also embedded in the document and a small group workshop was conducted on its use. The students who opted to take up the ePortfolio had no significant problems with its use, and could readily see its potential for job searching.

\section{Objectives of the current project}

The implementation of a University-wide ePortfolio has now moved into a new phase with the approval of funding for a project team to manage the deployment of a university-wide ePortfolio system.

After a review of a number of wiki, blog and ePortfolio tools on the market (both commercial and open source) the new Blackboard ePortfolio tool for $V$ ista has been identified as the tool that meets all current ePortfolio requirements, is tightly integrated with the University's learning management system and also has a range of other features attractive to ePortfolio users. The use of this tool will overcome the limitations of users' browsers identified in the 2006 trial. Pending satisfactory trials in Session 2 of 2006 and appropriate funding, the Blackboard ePortfolio tool for Vista could be implemented by February 2007.

Whilst the features of the tool, students access and readiness to use it are important considerations, from trial experience we consider that they are however not the largest hurdle to meeting the wider project aims to implement a single University-wide ePortfolio that is integrated into academic programs. As other researchers have noted, "a critical success factor for electronic portfolio implementation is a culture where faculty understand their central role in the portfolio process as resource providers, 
mentors, conveyors of standards, and definers of quality." (Gathercoal et al, 2002, p.30)

Therefore, the role of the project team is to ensure a quality, educationally sound implementation of the ePortfolio tool with a focus on faculty, school and discipline consultation to be able to customise the tool to allow students to reflect and store evidence of their achievements and learning against the University's Graduate Attributes, industry based Professional Skills, or a combination of both Graduate Attributes and Professional Skills. Due to the focus on the Graduate Attributes, another important success factor to this two-year project is the development of a culture where faculty and students better understand what these attributes mean and how they can best record, reflect and store evidence of them.

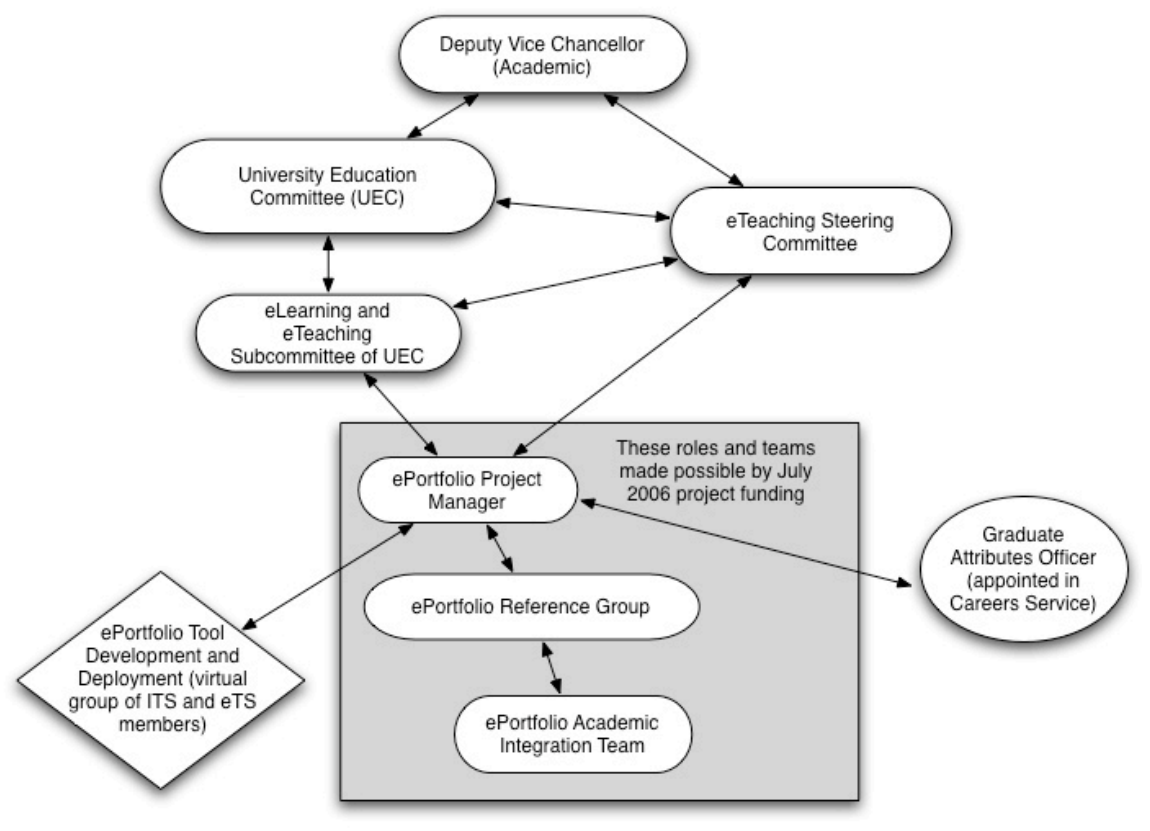

Figure 4: Student ePortfolio project structure

With the technology aspects of the ePortfolio tool (such as setting up the Blackboard ePortfolio for Vista tool trial) to be handled by existing proven structures for managing eTeaching at the University of Wollongong, primarily eTeaching Services of CEDIR collaborating with Information Technology Services, this leaves the focus of the funded ePortfolio project squarely on the academic aspects. 


\section{Project team structure}

Therefore, a project team structure has been developed with a Project Manager located in CEDIR (a central support unit) whose role involves liaison regarding the technology but is primarily responsible for overseeing two teams - one to guide the academic integration and the other, a reference group having representatives from each Faculty and Unit, to ensure their needs are met. In addition, a Graduate Attributes Project Officer was appointed to the Careers Service in 2006 on a range of projects including the ePortfolio project.

This new project structure responds to our own experience in the ePortfolio trials as well as the critical success factors for implementation developed by Gathercoal et al in 2002. By clustering the original list of twelve success factors into two categories - Technology and infrastructure, and Academic integration - we have been able to map out the scope of each team working on the project.

Table 1: Factors rearranged into technology infrastructure and academic integration arenas

\begin{tabular}{|c|c|}
\hline Technology and Infrastructure Arena & Academic Integration Arena \\
\hline Information Services Cooperation & Portfolio Culture \\
\hline Administrative Support & $\begin{array}{l}\text { "Implementing Force" and Project } \\
\text { Champions }\end{array}$ \\
\hline Technology Infrastructure & Implementation Milestones \\
\hline Training and Help Resources & Faculty Commitment \\
\hline $\begin{array}{l}\text { "Implementing Force" and Project } \\
\text { Champions }\end{array}$ & $\begin{array}{l}\text { Standards or Competency based } \\
\text { Curriculum }\end{array}$ \\
\hline Student Learning Centred Culture & $\begin{array}{l}\text { Feedback provided by supervisors and } \\
\text { mentors using the Webfolio/ePortfolio }\end{array}$ \\
\hline $\begin{array}{l}\text { Standards or Competency based } \\
\text { Curriculum }\end{array}$ & \\
\hline $\begin{array}{l}\text { Integrated curriculum developed by } \\
\text { teams of faculty }\end{array}$ & \\
\hline
\end{tabular}

The first four success factors from the Technology and Infrastructure Arena column are already present in the structure and relationship of eTeaching Services and Information Technology Services. The "Implementing Force" and Project Champions roles are encompassed by the the eTeaching Steering Committee as well as members of the e-Learning and Teaching sub committee of the University Education Committee, which includes representatives from every faculty and unit on campus. The latter three factors in this list are factors of the UoW teaching and learning environment, acknowledged by AUQA. 
This leaves the Academic Integration Arena, whose success factors become the focus of the newly formed ePortfolio Academic Integration team, set up for this particular project implementation.

The primary role of the Academic Integration team will be to look at best practice models of integrating reflective practice, Graduate Attributes / Professional Skills awareness and ePortfolio usage into the curriculum of programs. The ePortfolio Academic Integration team will further investigate and write guides for the three ePortfolio take up models already identified:

1. compulsory and assessed as part of a course;

2. introduced as a support resource to a course, however not directly assessed; and

3. optional and not assessed.

While this team is newly formed and will develop over the course of the program, it is expected that it will collaboratively develop a range of teacher centred support documents to assist faculties to integrate the ePortfolio into programs and courses in a pedagogically sound way, e.g. development of a "Tips for Reflective Practice" resource, learning designs for ePortfolios, a guide to running ePortfolio Induction and Orientation Sessions, and Good Practice Guidelines to Assessing ePortfolios.

In conversations with faculty as part of planning for the 2006 trial, it became obvious that in some areas a lack of 'portfolio culture' in paper based forms could also be a hurdle to moving forward - a factor also noted by Gathercoal et al (2002). In this instance it may be advantageous to first run paper based portfolio assignments to allow staff and students to become familiar with reflective practice and Graduate Attributes prior to moving into an ePortfolio. As Gathercoal et al (2002, p.30) noted, "Obtaining faculty participation is much easier when the academic unit already uses a paper portfolio process".

Therefore one strategy the project team are considering is to identify multiple subjects cross-campus with current portfolio or journal type assignments and target these for moving to ePortfolio tool within the same timeframe, supported by central staff development workshops. Another strategy will be to work with Faculty Education Committees and/or course coordinators to map these subjects in programs of study. This will identify if adequate subjects are actively participating, which utilise an 'optional' take up model and whether this is appropriate and desirable for that program. If necessary it may be useful to identify further subjects to assess the ePortfolio and work with subject coordinators to first implement paper based portfolios, prior to refining learning tasks and criteria, and moving to ePortfolios in subsequent teaching cycles. 


\section{Consultative framework}

Preliminary rounds of consultations with faculty staff and management have indicated that the new Graduate School of Medicine and the Faculty of Education will be the first implementers of ePortfolios at the University of Wollongong, having external accrediting body requirements to have them ready for February 2007. The Faculty of Engineering which has been moving forward strategically with Graduate Attributes and Professional Skills reviews is a likely second wave adopter, which will help it demonstrate its commitment to integrating Professional Skills across the entire program of study to its own accrediting body, Engineers Australia. In addition, the Faculty of Law, Faculty of Science and the School of Nursing are also in preliminary discussions about adopting ePortfolios with clusters of staff members in the Faculty of Arts and Faculty of Creative Arts also keen to proceed. Each has a slightly different context and policy mandate and these discussions indicate the complexity of faculty culture and the many factors that require consideration when developing 'implementation milestones' - another success factor.

Therefore the way forward involves a range of conversations and many decisions have to be made. The kinds of questions to be asked include:

- What level of awareness have staff and students of Graduate Attributes in this Faculty / School?

- Are there mandated or optional Professional Skills criteria for this Faculty/School?

- What level of awareness have staff and students with journaling or reflective practice in this Faculty/School?

- Have staff and students experienced a paper based or electronic portfolio in this Faculty/School?

- Are curriculum reviews on the near horizon as part of Faculty/School planning?

- What take up models do Faculty/School staff and management favour?

- What timeline is appropriate for implementing portfolios or ePortfolios in the Faculty/School?

To guide the process of ePortfolio implementation, the authors have developed a new consultative framework to ensure the implementation parallels faculty consultation about academic integration issues (see Figure 5). The framework starts with discussions leading to key decisions regarding ePortfolio implementation, for example, what set of criteria are students using to reflect and store evidence against? Staff demonstrations and tool customisation follow leading to a small scale pilot. This can run in parallel with discussions leading to appropriate subjects being chosen and appropriate learning tasks being refined to scaffold the ePortfolio use. 


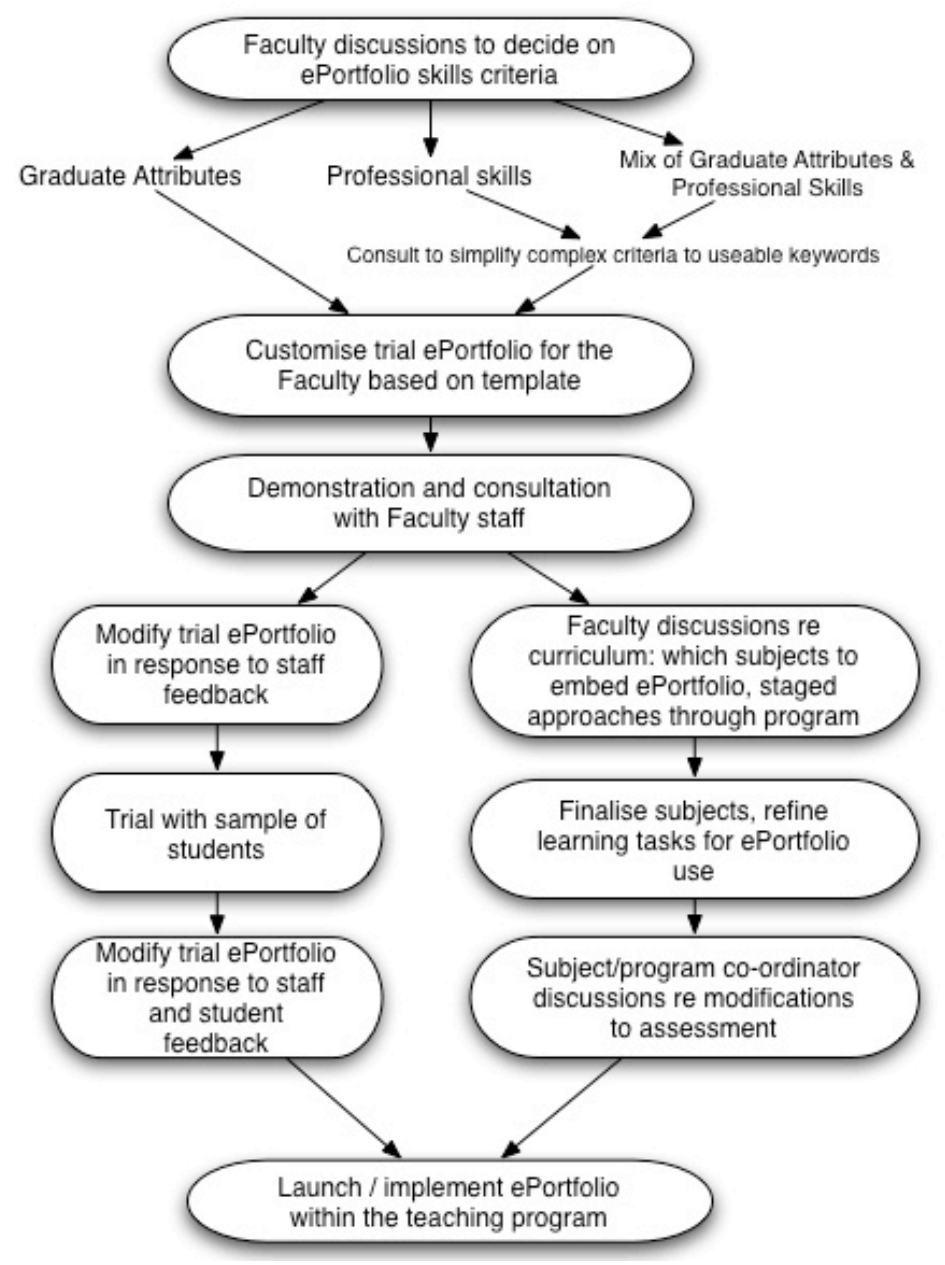

Figure 5: Consultative framework for developing Faculty based Student ePortfolios

The consultative framework process has already been used successfully in working with academics in the 2006 wiki trial. Since formally drawing up the schema we have also found it useful as a dissemination device in discussions with Faculty management and teaching staff to reassure them of their central role as decision makers in a localised, Faculty based implementation suitable to their needs, in which they are making key decisions and in which we have the skills and experience to guide and facilitate this process. It is expected that this will lead to increased faculty 
commitment to quality ePortfolio take up, which will be integral to the project's success.

\section{Conclusions and future directions}

There is still much work ahead to roll out the ePortfolio tool across campus over the two-year timeframe. The knowledge will build, and the approaches will be refined, including the consultative framework.

At the time of writing the ePortfolio for the Graduate School of Medicine has been built in the Blackboard Portfolio environment (see Figure 6), after a process of customisation (graphics, structure, goals) as per the consultative framework. The tool has allowed a centrally managed but Faculty based customisation process. The graphics and student support online module have been completed and built centrally to ensure quality and standardisation across the University. This was followed by release to the clients for customisation of website structure and goals in consultation with Faculty teaching staff, prior to return to the central unit for duplication and release to all students. A further seven ePortfolio templates are currently being developed for additional Faculties, Schools and Programs.

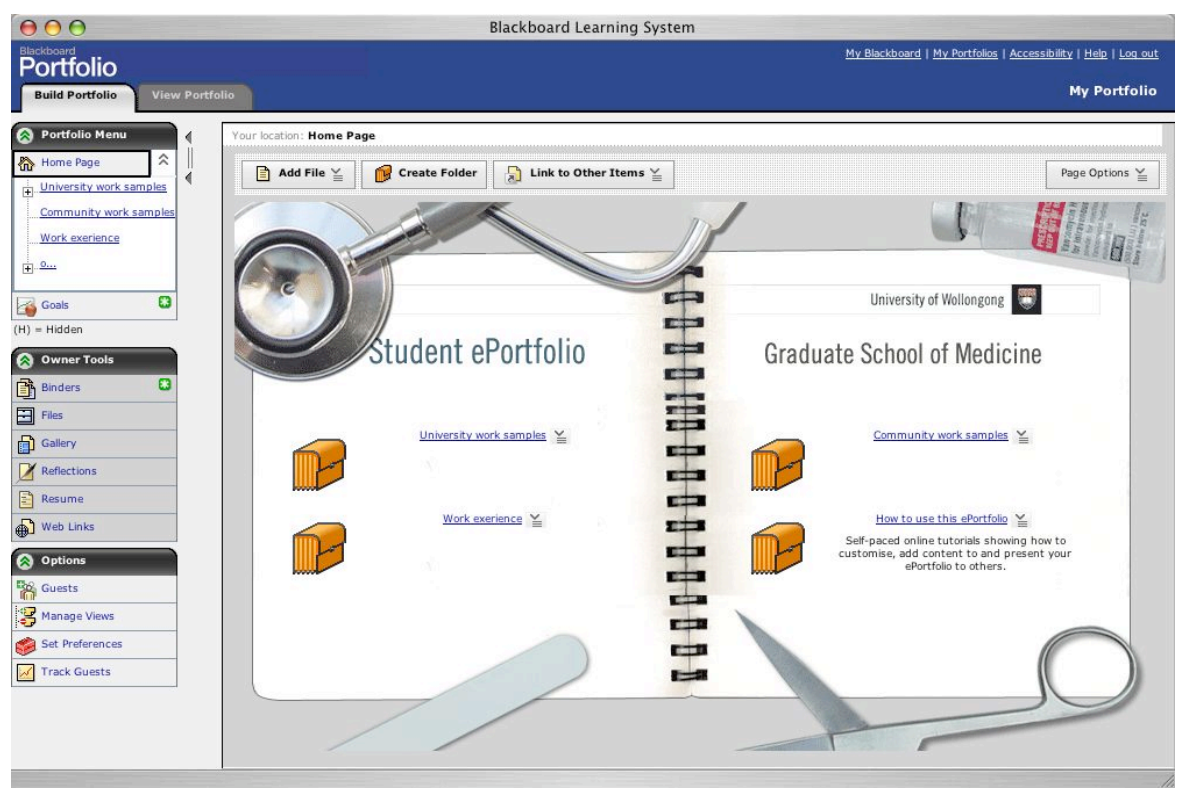

Figure 6: ePortfolio template for the Graduate School of Medicine, November 2006 
As we integrate the ePortfolio into new programs and subjects there will be further opportunity to evaluate the tool with both staff and students in different discipline contexts. In addition, further research into the kinds of learning designs, assessments and approaches which are useful as students progress from first year to third or fourth year of their undergraduate studies is an emerging area of interest.

\section{Acknowledgements}

The authors would like to thank Mr Martin Smith and Dr Kate Bowles for their involvement in the first ePortfolio trial. We would also like to thank Ms Lotte Latukefu and Associate Professor Stephen Tanner for their involvement in the 2006 ePortfolio trials. Thanks also to the Information Technology Services staff for their support in running the trials and exploring new ePortfolio possibilities.

\section{References}

Augar, N., Raitman, R. \& Zhou, W. (2004) Teaching and learning online with wikis. In R. Atkinson, C. McBeath, D. Jonas-Dwyer \& R. Philips (Eds), Beyond the confort zone: Proceedings of the 21st ASCILITE Conference (pp. 95-104). Perth, 5-8 December. http:/ / www.ascilite.org.au/conferences/perth04/procs/augar.html

Avraamidou, L \& Zembal-Saul, C. (2006). Exploring the influence of web-based portfolio development on learning to teach elementary science. AACE Journal, 14(2), 178-205. [2002 version at http:/ / eric.ed.gov:80/ERICWebPortal/ contentdelivery / servlet/ ERICServlet?accno=ED467271]

Barrett, H. (2001) Electronic Portfolios. [viewed 28 July 2006] http: / / electronicportfolios.com/portfolios/encycentry.pdf

Barrett, H. (2003). The Research on Portfolios in Education. [viewed 28 July 2006] http: / / www.electronicportfolios.com/ALI/ research.html

DiBiase, D. (2002). Using e-Portfolios at Penn State to enhance student learning. [viewed 28 July 2006] https:/ / www.e-education.psu.edu/portfolios/e-port_report.doc

Gathercoal, P., Love, D., Bryde, B. \& McKean, G. (2002). On implementing webbased electronic portfolios. Educause Quarterly, 2, 29-37. [verified 8 Feb 2007] http: / / www.educause.edu/ir/library/pdf/ eqm0224.pdf

Jafari, A. (2004). The "sticky" ePortfolio system: Tackling challenges and identifying attributes. Educause Review, July/ August, 38-48. [verified 8 Feb 2007] http:/ / www.educause.edu/ir/library/pdf/erm0442.pdf

Lamb, B. (2004). Wide open spaces: Wikis ready or not. Educause Review, September/October 2004, 36-48. [verified 8 Feb 2007] http: / / www.educause.edu/pub/er/erm04/erm0452.asp 
Luca, J., Polinelli, D. \& Howell, J. (2003). Creating e-portfolios to support student career opportunities. [viewed 27 July 2006] http: / / auc.uow.edu.au/conf/ conf03 / papers / AUC_DV2003_Luca2.pdf

MacKinnon, G. R. (1999). Electronic portfolios in pre-service science education. Technical Report, Acadia University, Eric No. ED437029. [verified 8 Feb 2007] http: / / eric.ed.gov/ERICWebPortal/ contentdelivery/servlet/ERICServlet?accn $\mathrm{o}=\mathrm{ED} 437029$

Ravet, S. (2005). EPortfolio for a learning society. eLearning Conference. [viewed 28 July 2006]. http:/ / www.elearningconference.org/Speakers_papers/Serge\% 20 Ravet $\% 20-\% 20$ Paper.doc

Reardon, R.C., Lumsden, J.A. \& Meyer, K.E. (2005). Developing an e-portfolio program: Providing a comprehensive tool for student development, reflection, and integration. NASPA Journal, 42(3), 368-380. [viewed 7 April 2006] http: / / publications.naspa.org/naspajournal/vol42/iss3/art6

Roberts, G., Aalderink, W., Cook, J., Feijen, M., Harvey, J., Lee, S. \& Wade, V.P. (2005). Reflective learning, future thinking: Digital repositories, e-portfolios, informal learning and ubiquitous computing. ALT/SURF/ILTA Spring Conference Research Seminar. [viewed 10 July 2006]. http:/ / www.alt.ac.uk/ALT_SURF_ILTA_white_paper_2005.pdf

Wood, D., Bruner, J.S. \& Ross, G. (1976). Role of Tutoring in Problem-Solving, Journal of Child Psychology and Psychiatry and Allied Disciplines, 17(2), 89-100.

Song, K., Scordias, M., Huang, C. \& Hoagland, C. (2004). Implementing e-portfolios in a university: An enterprise solution. Proceedings Society for Information Technology and Teacher Education (SITE) Conference. Atlanta, Georgia. [viewed 26 July 2006] http:/ / www.aace.org/dl/files/SITE2004/paper_3014_7985.pdf

This article received an Outstanding Paper Award at ASCILITE 2006, gaining the additional recognition of publication of an expanded version in AJET. The reference for the Conference version is:

Lambert, S. \& Corrin, L. (2006). Moving towards a university wide implementation of an ePortfolio tool. In Markauskaite, L., Goodyear, P. \& Reimann, P. (Eds), Who's Learning? Whose Technology? Proceedings of the 23rd ASCILITE Conference (pp. 441-450). Sydney, 3-6 December. http: / / www.ascilite.org.au/conferences/sydney06/ proceeding/ pdf_papers/p209.pdf

Ms Sarah Lambert, Manager, Learning Design Unit, CEDIR (Centre for Educational Development \& Interactive Resources), University of Wollongong, Wollongong NSW 2522, Australia.

Email: slambert@uow.edu.au

Ms Linda Corrin, Graduate Attributes Project Officer, Careers Service, University of Wollongong, Wollongong NSW 2522, Australia.

Email: lcorrin@uow.edu.au 